\title{
Effectiveness of Project Based Learning on Outcome Based Education- A case study
}

\author{
Prasanna Kumar MK', Soniya Agrawal ${ }^{2}$, Hemachandra Bhat ${ }^{3}$ \\ ${ }^{1}$ Department of Telecommunication, BMSCE, Bangalore \\ ${ }^{2}$ Department of Electrical and Electronics, BMSCE, Bangalore \\ ${ }^{3}$ Wipro Technologies, Bangalore \\ 'prasannamk.tce@bmsce.ac.in,'2soniyakagrawal@gmail.com, ${ }^{3}$ hemachandra.bhat@wipro.com
}

\begin{abstract}
The objective of this paper is to present the effectiveness of Project Based Learning incorporating the development of student's soft skills like communication and team work as well as technical or professional competences such as deep thinking and learning. A case study in the form of one month value added course on Project based learning using Unified Technology Learning Platform (UTLP) for Electrical cluster students is implemented. The learning outcome of the student is evaluated at regular intervals during the course. These outcomes are driven by institution's vision of the knowledge and skills that students need to acquire in order to be independent and a lifelong learner. This paper shows how project based learning can be used to facilitate for the production of qualified and well prepared professionals. This paper also presents an approach for the project assessment used to make the learning outcomes effectively.
\end{abstract}

\section{Prasanna Kumar MK}

Department of Telecommunication, BMSCE, Bangalore prasannamk.tce@bmsce.ac.in
Keywords:Outcome Based Education (OBE); Unified Technology Learning Platform(UTLP); Project Based Learning (PBL); Indusry Institute Interaction

\section{Introduction}

We live in a rapidly changing world driven by technology and economy necessitating the production of qualified and well prepared professionals. Project Based Learning (PBL) is one of the best proved methods to learn the concepts that exposed to the real world $\&$ product based problems and they can expand their learning experience. Project based learning is one way toaddress various skills at a time such as communication, collaboration, team work, and deep learning [1] .The objective of the study is to propose a new way of teaching the concepts of embedded system by implementing the project using UTLP development board and effective assessment of the projects which in turn accelerate the student's learning curve in this area. Out of the 12 Graduates Attributes (GA) of the NBA (National Board of Accreditation), GA1-GA4 highlights on the application of basic science/engineering concepts to solve, design, analyze systems/sub-systems in the core engineering domain. GA5 deals with the competency to use a modern engineering tool. GA6 and GA7 develop the awareness, concern and responsibility towards health, society and environment. GA8 emphasizes the importance of abiding by professional ethics, and the 
student is introduced to the norms of professional practice. GA9, measures the ability to perform as an individual/as a member of a diverse team. This attribute helps develop the competency to respect diverse cultures and perform in diverse teams, and thus prepares the skills necessary to pursue a professional career. GA10 emphasizes the need for effective communication, both with the engineering community and non-engineering community. GA11 takes the student through the norms of planning and implementing a project. GA12 attempts to measure the ability to engage in independent learning and the desire to continuously upgrade the knowledge [7]. These attributes are usually addressed by a significant number of courses or a laboratory component in a curriculum. But a single course may not address all the GA's required for a studentwhereas the same course if implemented through PBL addresses most of the 12 GA's much more effectively. The one month value added course was conducted in association with Mission10X, Wipro as part of the industry institute interaction. Mission10X initiative was launched on September 5, 2007 by Wipro Limited to address the challenges of employability in engineering education. Mission 10X chose to enhance the Graduate Engineering Attributes Viz., Deeper Learning, Communication Skills and Team Work in students to achieve this. The key focus was to develop a sustainable model. Though students are the end beneficiaries, it is not a feasible option to directly target them since this exercise would then have to be repeated year after year with new batches of students. It was in this context Mission10X adopted an innovative three-pronged approach in empowering faculty, developing transformative academic leaders and leveraging technology. The technology initiative specifically focuses on "Project Based Learning" through a Framework [8] which focuses on inculcating the Engineering Attributes apart from the industry specific processes in product engineering. This paper is organized as follows. Section II briefs about project based learning, Section III details the one month value added course conducted as a case study, Section IV explains the assessment method of this course. Section V deals with the outcome of the course and finally we conclude the paper in section VI.

\section{Projet Based Learning}

\section{A. What is Project Based Learning}

Project Based learning is a systematic teaching method that engages learners in acquiring knowledge and skills through an extended inquiry process structured around complex, relevant questions, carefully designed products, and authentic tasks and skills[1].

\section{B. Impact of PBL on OBE}

Outcome based learning is created to focus on empirically measuring student's performance. This performance is called outcome. The objective of OBE is to ensure the students have the ability to understand the outcome determined by the facilitator [2]. Students learn more deeply when they can apply classroom-gathered knowledge to real-world problems, and when they take part in projects that require sustained engagement and collaboration within the team as well as outside their team. Activelearning practices have a more significant impact on student performance than any other variable, including student background and prior achievement. Students are most successful when they are taught how to learn as well as what to learn [3].

\section{Value Added Course}

The value added course is planned during the summer vacation for second and third year electrical cluster students with an objective to introduce project based learning to accomplish deep learning, communication skill and team work and to make them well prepared professionals. The course introduce the participants to the Wipro UTLP (Unified Technology Learning Platform) development board along with modern tools like Eclipse, ULK control panel under Linux environment and Embedded C Programming. This course will also enable them to continue the usage of this kit further during their engineering program.It was a four week course without any credit allotted and the project is implemented using waterfall development methodology, it is divided into five major phases as suggested by the Learning Framework (LF) given by Wipro Mission 10 X [8] to meet the industry standard outcomes in both learner and facilitator. The 5 phases of the project based learning that we implemented in our course are
口 Feature requirements/Feature finalization
๑ Design
૫ Implementation
口 Testing
c Documentation/Maintenance 


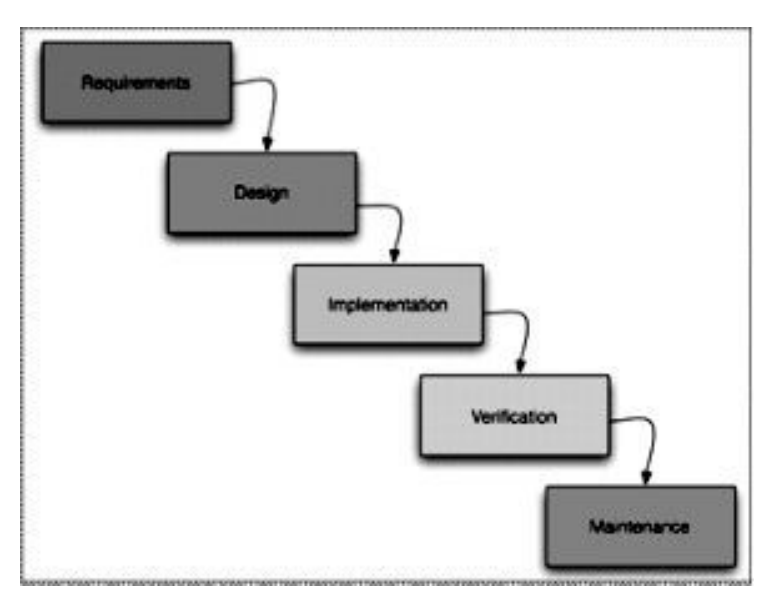

Fig.1 waterfall development methodology

Fig. 1 shows the waterfall development methodology for the project implementation. The waterfall model was first defined by Winston W. Royce in 1970 [9] and has been widely used for software projects ever since. When using this methodology it is vital that all requirements are captured during the Requirements/design phase as it can be very expensive to re-visit requirements once implementation (coding) has begun. When done well the waterfall method is excellent for large projects and there are no surprises when the application is finally delivered as all features and even the appearance of the application has been fully specified and understood by future users of the system. If the requirements phase is not meeting the required standard the waterfall method delivers failure as the end result will only be as good as the specifications [4].

\section{Advantages of the waterfall method [5]}

- Design errors are captured before any software is written saving time during the implementation phase.

- Excellent technical documentation is part of the deliverables and it is easier for new programmers to get up to speed during the maintenance phase.

- The approach is very structured and it is easier to measure progress by reference to clearly defined milestones.

- The total cost of the project can be accurately estimated after the requirements have been defined (via the functional and user interface specifications).

- Testing is easier as it can be done by reference to the scenarios defined in the functional specification.

Each of these steps is further divided into four major steps, to insure the achievement of each phase outcome as shown in Fig.2.

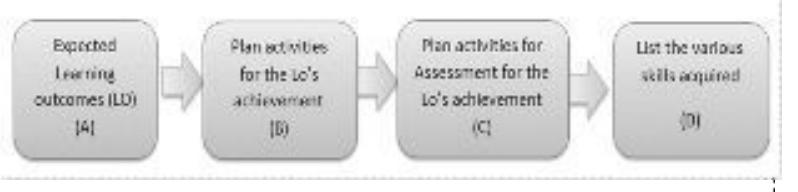

Fig.2.Learning frame work for each phase of the project

Fig 2 shows the various stages of learning frame work for each phase of the project to achieve the expected learning outcomes.For example, in a project titled "Assembly Line Monitoring System".

A. Feature finalization phase (Expected Learning outcomes (LO)) of learning frame work can be as follows.

My learners will be able to,

- Understand the basic requirements of an industry that uses an assembly line.

- Identify the features of the Assembly line monitoring system.

- Prioritize the features required for an assembly line for project implementation.

- Importance of user perspective in project development.

B. Plan/Activity to achieve the expected (Los)

My Learners will,

- Identify a set of features required for the intended Assembly line monitoring system by interacting with the industry.

- Make a visit to various industries that uses an assembly line and understand the manager - operator workloads.

- Prepare a questionnaire and observe the same at various industries in and around the location of the project and other nations with the help of information available on internet.

- Analyze the data collected through the collected information and infer the requirement of the user.

- List features of the Assembly line monitoring system corresponding to the requirement of the industry.

- Select some of the listed features based on priority and feasibility. 
C. Plan / Activity to determine whether and how much LOs has been achieved

My Learners have to provide justification (through oral presentation) on,

․ The prepared questionnaire for features.

口 Amount of data collected (how much is sufficient/necessary etc.)

口 Method used for analysis of the collected information (based on various parameters such as cost, no. of users, technology)

口 Reasoning used for prioritizing the features and final selection (what is the criterion used for prioritizinge.g. cost/simplicity / feasibility/)

\section{Acquired skill(s)/Technical ability}

口 Collaborative working through team work

口 Communication (oral and written)

口 Knowledge of survey question preparation

૫ Data analysis

૫ Logical reasoning

口 Industry Requirements

The value added course introduced the participants to the Wipro UTLP (Unified Technology Learning Platform) kit along with tools like Eclipse, ULK control panel under Linux environment and Embedded ' $\mathrm{C}$ ' Programming. Thirteen teams were framed with multidisciplinary students, 3 in each team to maintain deep learning, communication skill and team work.Fig 3 shows some of the student's projects implemented using UTLP kit.

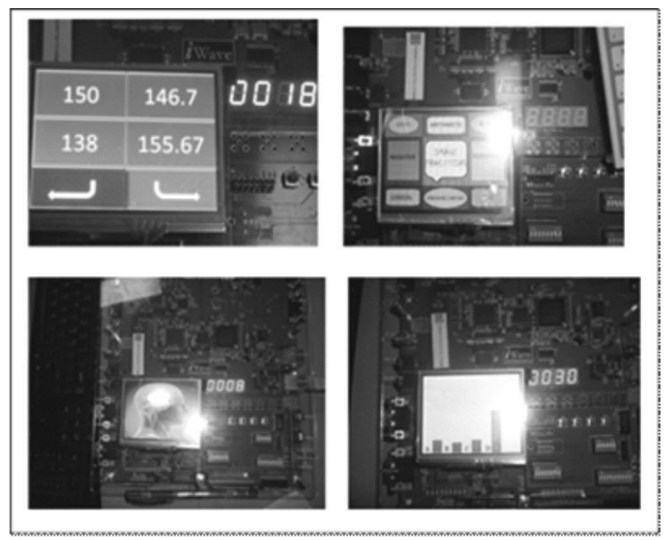

Fig.3 Demo of few projects implemented using UTLP kit.

\section{Course Assessment}

The course assessment and evaluation on the implementation of a Project Based Learning (PBL) incorporating the development of students' soft skills as well as Technical or professional competences are discussed in this section. It should be noted that the students were not graded but were assessed to check the requirement level of the project. Evaluation was done in two phases mid evaluation and final evaluation. Mid evaluation: During the midevaluation of the project work students showed their progress and some of the key inputs given by evaluator from industry about project work. Final evaluation: All the thirteen teams were able to present their projects using UTLP kits and final evaluation was done jointly by the internal faculty and delegate from industry with the predefined rubric as indicated in Table-I. Each row in Table-I is assessed on a 10 point scale.

Table1: Sample project evaluation sheet for 2 teams

\begin{tabular}{|c|c|c|c|}
\hline & Criteria & Team 1 & Team2 \\
\hline \multirow[t]{6}{*}{1} & Learning Outcomes & & \\
\hline & $\begin{array}{l}\text { Phase1 (Finalizing } \\
\text { feature) }\end{array}$ & 9 & 6 \\
\hline & Phase 2 (Design) & 6 & 5 \\
\hline & Phase3 (Implementation) & 9 & 6 \\
\hline & Phase 4 (Testing) & 8 & 6 \\
\hline & Phase 5 (Documentation) & 9 & 5 \\
\hline 2 & Successful demonstration & 10 & 6 \\
\hline \multirow[t]{7}{*}{3} & Communication & & \\
\hline & Specification document & 7 & 4 \\
\hline & Design document & 6 & 4 \\
\hline & Test report & 8 & 6 \\
\hline & Release document & 9 & 7 \\
\hline & Final presentation & 10 & 4 \\
\hline & Systematic Coding & 9 & 7 \\
\hline \multirow[t]{3}{*}{4} & Team work & & \\
\hline & Within their own project & 10 & 8 \\
\hline & With any other & 9 & 7 \\
\hline 5 & User focus in the project & 7 & 5 \\
\hline \multirow[t]{2}{*}{6} & CVS usage (mandatory) & 10 & 8 \\
\hline & Total (160) & 136 & 94 \\
\hline
\end{tabular}




\section{Outcome of the Course}

The outcome of the value added course is measured with respect to the overall project evaluation sheet for all the teams and also by identifying the Graduate attributesaddressed with and without project based learning for embedded systems. Also at the end of the course feedback is collected from the learners about the course conduction to have closed loop and continuous improvement in the teaching learning methodology.Table II shows the comparison of 12 Graduate Attributes addressed with project based leaning and regular embedded system course without projects. As shown by the table almost all the graduate attributes are achieved by project based learning. Please note that the comparison is done only for a regular subject without practical experiments. This comparison should not be done with a regular course on project work. At the end of the course the students were asked to give the feedback about the course. It was observed that majority of the students were satisfied with the conduction and outcomes of the course.

Table 2 Comparison of GA's addressed for a course with And without PBL

\begin{tabular}{|c|c|r|c|}
\hline Graduate Attributes & $\begin{array}{c}\text { With } \\
\text { PBL }\end{array}$ & $\begin{array}{c}\text { With out } \\
\text { PBL }\end{array}$ \\
\hline 1 & Engineering knowledge & $\checkmark$ & $\checkmark$ \\
\hline 2 & Problem analysis & $\checkmark$ & $\checkmark$ \\
\hline 3 & Design/development & $\checkmark$ & \\
\hline 4 & Conduct investigations & $\checkmark$ & \\
\hline 5 & Modern tool usage & $\checkmark$ & \\
\hline 6 & The engineer and society & $\checkmark$ & $\checkmark$ \\
\hline 7 & Environment issues & $\checkmark$ & $\checkmark$ \\
\hline 8 & Ethics & $\checkmark$ & $\checkmark$ \\
\hline 9 & Team work & $\checkmark$ & \\
\hline 10 & Communication & $\checkmark$ & \\
\hline 11 & Project management & $\checkmark$ & \\
\hline 12 & Life-long learning & $\checkmark$ & \\
\hline
\end{tabular}

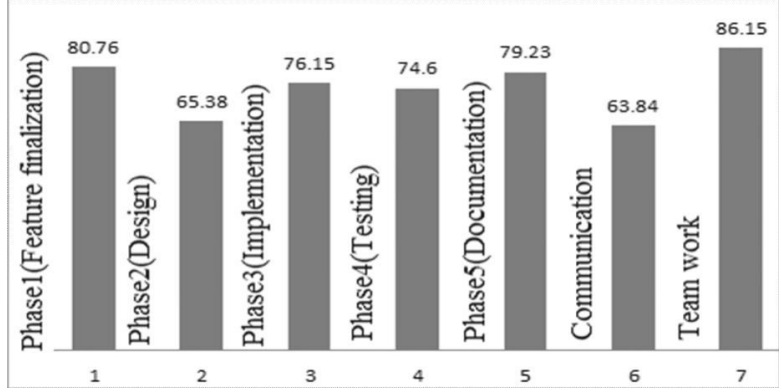

Fig.4. Measure of the outcomes at various phases of the course with PBL (All values are in percentage)
Fig.4. Measure of the outcomes at various phases of the course with PBL (All values are in percentage)

The Fig.4 shows the measure of outcomes at various phases of the project based learning. The values are calculated using result sheet as shown in the Table I by considering all 13 teams into account to measure the efficiency of this embedded course with project based learning.

\section{Conclusions}

We can address various GAs either through theory course or through a laboratory component. But it is not guaranteed to address maximum number of GAs in a single course at a time. A separate course on Project work can address team work, communication skills but it is not guaranteed to focus on deep learning as it is graded at the end of the semester. So PBL helps in deep thinking and learning along with communication skills and team work within the team as well as with other team members which can lead to collaborative projects. Best part of the value added course is that it is kept out of academics without associating any grades. This promotes the learner to go for deep learning instead at the surface level that normally happens in any other course without PBL.

\section{Acknowledgement}

We would like to thank Dr. B. Kanmani, Professor \& Head Dept.of Telecommunication, Dr.Ravishankar Deekshit, Professor \& Head, Dept. of Electrical\& Electronics and Dr. A.Usha, Professor \& UTLP Coordinator, BMS College of Engineering for their constant support in implementing this PBL based value added course for undergraduate students. We also thank Dr. Mallikharjuna Babu, Principal, BMSCE and Mr. P.B. Kotur, General Manager and Head Mission10X for the constant support. The work reported in this paper is supported by the college through the Technical Education Quality Improvement Programme [TEQIP].

\section{References}

[1] http://bie.org/images/uploads/general/20fa $7 \mathrm{~d} 42 \mathrm{c} 2$ 16e2ec171a212e97fd4a9e.pdf (Introduction to Project Based Learning Handbook, Buck Institute for Education.)

[2] Ahmad Saiful Azlin Puteh Salin, "Outcome-based learning and modified problem-based learning for accounting education" 010 International 
Conference on Economics, Business and Management IPEDR vol.2 (2011) C (2011) IAC S IT Press, Manila, Philippines

[3] Akash Kumar, "Project-Based Learning in Embedded Systems Education Using an FPGA Platform," IEEE transactions on education, vol. 56, no. 4, november 2013.

[4]http://learnaccessvba.com/application_developme nt/waterfall_method.htm (waterfall method)

[5] Roslan Hashim Yorozu, , "Implementing Outcome Based Education Using Project Based Learning at University of Malaya ," European Journal of Scientific Research ISSN 1450-216X Vol.26 No.1
(2009), pp.80-86 EuroJournals Publishing, Inc. 2009 http://www.eurojournals.com/ejsr.htm .

[6] B. Kanmani, K. Mallikharjuna Babu. "Continuous Improvements in Teaching-learning-process in Outcomes Based Education"

[7] B. Kanmani, K. Mallikharjuna Babu. "Leveraging technology in outcome based education" ICTIEE 2014, Hubli,Karnataka

[8]http://www.mission10x.com/m10x/technology/le arning/practitioner (Learning Framework)

[9] https://en.wikipedia.org/wiki/Winston_W._Royce (Water fall model) 